\title{
A Preliminary Survey of the Non-biting Midges (Diptera: Chironomidae) of the Dominican Republic
}

\author{
Fabio Laurindo da Silva ${ }^{1, *}$, Sofia Wiedenbrug ${ }^{2}$ and Brian D. Farrell ${ }^{1}$ \\ ${ }^{1}$ Museum of Comparative Zoology, Department of Organismic and Evolutionary Biology, Harvard Uni- \\ versity, 26 Oxford Street, Cambridge, MA 02138, USA. \\ E-mails: laurindodasilva@fas.harvard.edu,bfarrell@fasmail.harvard.edu \\ ${ }^{2}$ Zoologische Staatssammlung München, Münchhausenstr. 21, 81247 München, Germany. \\ E-Mail: sofia.wig@gmail.com \\ ${ }^{*}$ Corresponding author.
}

\begin{abstract}
Chironomidae (Diptera) are among the most diverse and widespread aquatic insects, with roughly 5,500 described species. However, prior to the present work, no species of Chironomidae had been documented from the island of Hispaniola. Collections of non-biting midges, with emphasis on the lotic fauna, were made in the Dominican Republic during July of 2015. In total, 578 specimens belonging to 27 genera and at least 44 species within the subfamilies Chironominae (20 taxa), Orthocladiinae (16 taxa) and Tanypodinae (8 taxa) were found. The subfamilies Chironominae and Orthocladiinae predominated. Polypedilum was the most widespread and diverse genus of Chironominae. Metriocnemus were collected in bromeliad tanks. The chironomid fauna in Dominican Republic includes multiple genera with worldwide distributions, including Holarctic and Neotropical components.
\end{abstract}

\section{Introduction}

Non-biting midges, belonging to the family Chironomidae (Diptera), are the most widely distributed free-living holometabolous insects (Ferrington 2008). The immature stages of most species occur in freshwater, but numerous terrestrial or marine species are known (Sæther and Ekrem 2003). The adult life stage of chironomids is short, and most of the lifespan is spent as a larva. The great species and habitat diversity makes this family not only a valuable indicator species for lentic and lotic aquatic ecosystems, but also a most interesting group for phylogenetic and biogeographical analyses (Silva and Ekrem 2015). However, in order to obtain the most biologically informative data, it is crucial to determine taxa to species, since within a single genus, species may respond in a different way to environmental changes (Lenat and Resh 2001). Usually, the lack of descriptions and keys to a local fauna prevents species identifications, or workers choose to overlook the Chironomidae in favor of groups (e.g. Ephemeroptera, Plecoptera, Trichoptera) that are more restricted in number and diversity (Spies et al. 2009).

Approximately 900 chironomid species are recognized from the Neotropical region (M. Spies, personal communication). This number has been increasing in recent years thanks to intense taxonomic work being done, particularly in Brazil (e.g. Andersen and Pinho 2014, Andersen et al. 2015, Oliveira et al. 2013, Silva and Wiedenbrug 2015, Silva et al. 2014a,b, Siri and Donato 2015, Trivinho-Strixino et al. 2013, 2015). Regarding Central America and the Caribbean, the chironomid fauna remains poorly known. No list of Chironomidae in Dominican Republic has been published so far and our knowledge consists basically of fossil records (Grund 2004, 2006, Perez-Gelabert 2008). Recent fauna have been sparsely mentioned by some authors. Margalef (1986), investigating the limnology of Lake Enriquillo in Dominican Republic, documented some chironomid larvae, identified only to family. Moreover, Perez-Gelabert (2008) compiled a checklist of arthropods of Hispaniola, which included chironomid species in amber and only one recent species, Chironomus redeuns Walker, considered a nomen dubium by Spies and Reiss (1996). In this context, the goal of our study was to provide data on the Chironomidae of the Dominican Republic, in order to contribute to the overall knowledge of Caribbean fauna.

\section{Material and Methods}

\section{Study area}

Hispaniola (Fig. 1) is the second largest island $\left(76,480 \mathrm{~km}^{2}\right)$ in the archipelago of the Greater Antilles, Caribbean Region. It is centrally located in the Caribbean basin just south of the Tropic of Cancer at $17^{\circ} 40^{\prime}$ and $19^{\circ} 56^{\prime}$ North latitude and $68^{\circ} 20^{\prime}$ and $72^{\circ} 01^{\prime}$ 'West longitude. This natural geographic unit is shared by two countries with different languages and cultures, Haiti on the western one third $\left(27,750 \mathrm{~km}^{2}\right)$ and the Dominican Repub- 
lic on the eastern two thirds $\left(48,730 \mathrm{~km}^{2}\right)$ (PerezGelabert 2008). The Dominican shores are washed by the Caribbean to the south and the Atlantic Ocean to the north. It has a varied terrain comprising rainforest, savannah and highlands, including Pico Duarte which, at about $3100 \mathrm{~m}$ elevation, is the Caribbean's tallest mountain. Climate in the Dominican Republic is tropical maritime, ranging from 18 to $32^{\circ} \mathrm{C}$, with relatively high humidity. Mean annual precipitation along the southeastern coast around Santo Domingo is $1,400 \mathrm{~mm}$ with a distinct wet season from May to October. The island has some large saline or hypersaline inland lakes. There are several smaller islands and cays that are part of the Dominican territory. A complex topography and variety of local weather patterns generate numerous microhabitats, which support a rich flora and fauna with significant numbers of endemic species (Perez-Gelabert 2008).

\section{Collection and identification}

Collections were made at 13 localities in July 2015 (Table 1, Fig. 1). Most were lotic environments, ranging from small springs to large rivers, at elevations from 20 to $2,250 \mathrm{~m}$ above sea level. The main emphasis was on adult sampling, collected with a sweep net near aquatic systems. Dipnets

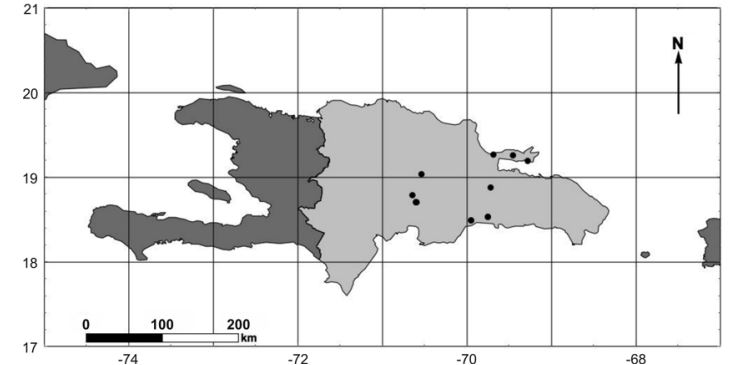

Figure 1. Map of the island of Hispaniola showing collecting localities in Dominican Republic (shown in light grey shading). Sampling sites are denoted as black dots. Some sites overlap due to their proximity and scale of map. See table 1 for more details on sampling localities.

(20 $\mathrm{cm} \mathrm{dia,} 250 \mu \mathrm{m}$ mesh) were used to collect immatures at some localities. Samples were also taken by aspiration of the water and organisms from the central tank of bromeliads. All samples were field-preserved using $96 \%$ ethanol. In the laboratory, after initial sorting and identification, representatives of every taxon in each sample were slide mounted in Euparal for species identification following the procedure outlined by Pinder (1983, 1986, 1989). Voucher specimens will be deposited in the Museum of Comparative Zoology at Harvard University.

Table 1. Localities, habitat type and geographic coordinate of chironomid collections in the Dominican Republic, July 2015.

\begin{tabular}{|c|c|c|c|c|}
\hline Code & Province & Habitat type & Latitude & Longitude \\
\hline A & Santo Domingo & River, heavy organic pollution & $18^{\circ} 31^{\prime} 52.2^{\prime} \mathrm{N}$ & $69^{\circ} 45^{\prime} 12.7^{\prime \prime} \mathrm{W}$ \\
\hline B & Samaná & River, with rocky bottom & $19^{\circ} 16^{\prime} 06.2^{\prime \prime} \mathrm{N}$ & $69^{\circ} 41^{\prime} 15.7^{\prime \prime} \mathrm{W}$ \\
\hline $\mathrm{C}$ & La Vega & Pool, surrounded by grass & $18^{\circ} 42^{\prime} 15.8^{\prime \prime} \mathrm{N}$ & $70^{\circ} 36^{\prime} 14.3^{\prime \prime} \mathrm{W}$ \\
\hline $\mathrm{D}$ & Santo Domingo & Lake, without surrounding vegetation & $18^{\circ} 29^{\prime} 42.3^{\prime \prime} \mathrm{N}$ & $69^{\circ} 57^{\prime} 15.9^{\prime \prime} \mathrm{W}$ \\
\hline $\mathrm{E}$ & La Vega & Stream, with sparse riparian vegetation & $18^{\circ} 42^{\prime} 23.1^{\prime \prime} \mathrm{N}$ & $70^{\circ} 36^{\prime} 12.7^{\prime \prime} \mathrm{W}$ \\
\hline $\mathrm{F}$ & La Vega & River, with moderate canopy cover & $19^{\circ} 02^{\prime} 10.0^{\prime} \mathrm{N}$ & $70^{\circ} 32^{\prime} 35.2^{\prime \prime} \mathrm{W}$ \\
\hline G & Santo Domingo & River, heavy organic pollution & $18^{\circ} 31^{\prime} 51.1^{\prime \prime} \mathrm{N}$ & $69^{\circ} 45^{\prime} 12.8^{\prime \prime} \mathrm{W}$ \\
\hline $\mathrm{H}$ & Samaná & River, with dense canopy cover & $19^{\circ} 15^{\prime} 48.5^{\prime \prime} \mathrm{N}$ & $69^{\circ} 27^{\prime} 29.9^{\prime \prime} \mathrm{W}$ \\
\hline I & Santo Domingo & River, heavy organic pollution & $18^{\circ} 29^{\prime} 41.5^{\prime \prime} \mathrm{N}$ & $69^{\circ} 56^{\prime} 59.6^{\prime \prime} \mathrm{W}$ \\
\hline $\mathrm{J}$ & Monte Plata & Stream, with dense riparian vegetation & $18^{\circ} 52^{\prime} 46.6^{\prime \prime} \mathrm{N}$ & $69^{\circ} 43^{\prime} 20.7^{\prime \prime} \mathrm{W}$ \\
\hline K & Samaná & Stream, with moderate canopy cover & $19^{\circ} 11^{\prime} 32.9^{\prime \prime} \mathrm{N}$ & $69^{\circ} 17^{\prime} 04.5^{\prime \prime} \mathrm{W}$ \\
\hline $\mathrm{L}$ & La Vega & River, surrounded by grass & $18^{\circ} 47^{\prime} 32.4^{\prime \prime} \mathrm{N}$ & $70^{\circ} 38^{\prime} 46.9^{\prime \prime} \mathrm{W}$ \\
\hline M & La Vega & Bromeliad tanks & $18^{\circ} 42^{\prime} 15.9^{\prime \prime} \mathrm{N}$ & $70^{\circ} 35^{\prime} 56.0^{\prime \prime} \mathrm{W}$ \\
\hline
\end{tabular}




\section{Results}

In total, 578 representatives of three subfamilies were collected (Table 2). Twenty-seven genera have been identified, containing at least 44 species. At least two additional orthoclad species could not be assigned to any described genera. Chironominae and Orthocladiinae predominated in all samples. Tanypodinae were often sampled, but rarely in large numbers. Chironomini was represented by at least 10 genera, but species diversity was low. Except for Polypedilum, no genus was represented by more than two species. The most widespread Chironomini were Polypedilum (Asheum) beckae (Sublette) and other Polypedilum spp. Polypedilum is one of the largest chironomid genera containing about 440 described species (Saether et al. 2010). Larvae of Polypedilum occur in virtually all kinds of still and flowing waters. A few species are also found in bromeliad tanks (Epler et al. 2013). Other commonly encountered Chironominae were Goeldichironomus spp. With the exception of Chironomus sp., Paralauterborniella nigrohalteralis and Stenochironomus sp. 1, collected in two localities, the remaining species were rare and found in only one locality. Two species of Stenochironomus and one of Xestochironomus were found, the larvae of these genera are often found mining decayed leaves or wood in freshwater habitats, which suggests woody debris as an available food item in those streams. The tribe Pseudochironomini was represented by Manoa pahayokeensis Jacobsen \& Perry and Pseudochironomus sp., while Tanytarsus was the only genus belonging to Tanytarsini.

Ten genera of Orthocladiinae have been identified. Except for Cricotopus, most of these were collected from single localities. Compterosmittia croizati Mendes, Andersen \& Saether and a related, undescribed species were collected in three localities in Dominican Republic. Furthermore, numerous larvae of Metriocnemus were collected in bromeliad tanks at the base of leaves, petals or bracts. Metriocnemus is a cosmopolitan midge with seven endemic species from the Neotropics and commonly found in pitcher plants, hollow trees and phytotelmata (Siri and Donato 2014). Despite much searching near the bromeliad phytotelmata where larvae were found, no adults of Metriocnemus were collected. Finally, several specimens belonging to Diplosmittia were collected at the National Botanical Garden (Santo Domingo) in a highly organic, polluted river. The examination of this not readily identifiable material, suggests that this species does not belong to any of the currently recognized Diplosmittia species. The new species can be separated from other Diplosmittia by the narrow and elongate anal point. The description of the new species will be done in a later manuscript.

Tanypodinae was the least abundant subfamily sampled in the Dominican Republic. Pentaneurini was represented by at least four genera with very low species diversity. Labrundinia was represented by three morphospecies, while Pentaneura by two. There appear to be numerous undescribed species of Labrundinia from the Neotropical region (Roback 1987). In a worldwide revision of the genus Silva et al. (2014a) described four species of $L a b$ rundinia from Central America. However none of the Dominican species could be ascribed to any of the previously described species. Only immatures of Thienemannimyia were collected. Although we assigned these specimens to Thienemannimyia, an identification of Thienemannimyia group (Silva and Ekrem 2015) may be more appropriate since the immatures of this complex are difficult to separate at the generic level (Cranston and Epler 2013). Only one pupal exuviae belonging to Procladius (Holotanypus) was collected.

Table 2. Chironomid taxa collected in the Dominican Republic, July 2015. A = adult, $\mathrm{L}=$ larva, $\mathrm{P}=$ pupal exuviae. Localities according to the table 1 .

\begin{tabular}{lll}
\hline Chironomidae taxa & Life Stage & Locality \\
\hline
\end{tabular}

Chironominae

Chironomini

Chironomus sp.

Einfeldia sp.

Goeldichironomus sp. 1

Goeldichironomus sp. 2

Microchironomus sp.

$\begin{array}{ll}\text { A, L } & \text { A, H } \\ \text { A } & \text { H } \\ \text { A } & \text { G, H } \\ \text { A } & \text { A, G } \\ \text { A } & \text { D }\end{array}$

A, L

, H

$\mathrm{G}, \mathrm{H}$

A, G 


\begin{tabular}{|c|c|c|}
\hline Chironomidae taxa & Life Stage & Locality \\
\hline Parachironomus yanomani Spies, Fittkau \& Reiss & A & $\mathrm{D}$ \\
\hline Paralauterborniella nigrohalteralis (Malloch) & A & $\mathrm{C}, \mathrm{H}$ \\
\hline Polypedilum (Asheum) beckae (Sublette) & A & $\mathrm{A}, \mathrm{D}, \mathrm{G}, \mathrm{H}$ \\
\hline Polypedilum sp. 1 & A & $\mathrm{B}, \mathrm{E}, \mathrm{J}, \mathrm{K}, \mathrm{L}$ \\
\hline Polypedilum sp. 2 & $\mathrm{~A}$ & $\mathrm{~B}, \mathrm{~F}, \mathrm{H}, \mathrm{K}$ \\
\hline Polypedilum sp. 3 & $\mathrm{~A}$ & $\mathrm{H}, \mathrm{J}$ \\
\hline Polypedilum sp. 4 & $\mathrm{~A}$ & $\mathrm{H}$ \\
\hline Polypedilum sp. 5 & $\mathrm{~A}$ & $\mathrm{H}$ \\
\hline Stenochironomus sp. 1 & $\mathrm{~A}$ & $\mathrm{H}, \mathrm{J}$ \\
\hline Stenochironomus sp. 2 & A & $\mathrm{H}$ \\
\hline Xestochironomus sp. & A & $\mathrm{H}$ \\
\hline \multicolumn{3}{|l|}{ Pseudochironomini } \\
\hline Manoa pahayokeensis Jacobsen \& Perry & $\mathrm{A}$ & $\mathrm{J}$ \\
\hline Pseudochironomus sp. & $\mathrm{A}, \mathrm{P}$ & $\mathrm{L}$ \\
\hline \multicolumn{3}{|l|}{ Tanytarsini } \\
\hline Tanytarsus excavatus group & $\mathrm{P}$ & $\mathrm{C}, \mathrm{L}$ \\
\hline Tanytarsus sp. & A & $\mathrm{H}$ \\
\hline \multicolumn{3}{|l|}{ Orthocladiinae } \\
\hline Antillocladius sp. & A & $\mathrm{F}$ \\
\hline Compterosmittia croizati Mendes, Andersen \& Saether & $\mathrm{A}$ & $\mathrm{H}, \mathrm{I}$ \\
\hline Compterosmittia sp. 1 & A & $\mathrm{D}$ \\
\hline Cricotopus sp. 1 & A & $\mathrm{B}, \mathrm{C}, \mathrm{D}, \mathrm{H}$ \\
\hline Cricotopus sp. 2 & A & $\mathrm{B}, \mathrm{H}, \mathrm{J}$ \\
\hline Diplosmittia $\mathrm{sp}$ & A & I \\
\hline Lipurometriocnemus glabalus Sæther & A & $\mathrm{C}$ \\
\hline Lipurometriocnemus sp. & A & $\mathrm{F}$ \\
\hline Metriocnemus sp. & $\mathrm{L}$ & M \\
\hline Orthocladiinae sp. 1 & $\mathrm{~A}$ & $\mathrm{H}$ \\
\hline Orthocladiinae sp. 2 & A & $\mathrm{J}$ \\
\hline Orthocladius sp. & A & $\mathrm{D}$ \\
\hline Parametriocnemus sp. & A & $\mathrm{L}$ \\
\hline Psectrocladius sp. 1 & $\mathrm{~L}, \mathrm{P}$ & $\mathrm{L}$ \\
\hline
\end{tabular}




\begin{tabular}{lll}
\hline Chironomidae taxa & Life Stage & Locality \\
\hline Psectrocladius sp. 2 & L & C \\
Pseudosmittia sp. & A & D \\
Tanypodinae & & \\
Pentaneurini & & \\
Labrundinia sp. 1 & A & H \\
Labrundinia sp. 2 & A & H, J \\
Labrundinia sp. 3 & A & H \\
Monopelopia sp. & A & A, K, L \\
Pentaneura sp. 1 & A & J \\
Pentaneura sp. 2 & A & F, H \\
Thienemannimyia sp. & A, P & E \\
Procladiini & & \\
Procladius (Holotanypus) sp. 1 & P & C \\
\hline
\end{tabular}

\section{Discussion}

At the generic level the chironomid fauna in Dominican Republic includes multiple genera with worldwide distributions with Holarctic and Neotropical components. The Neotropical component is typically an extension of the warm adapted fauna of lowland South America (Watson and Heyn 1992). At the level of species it is possible to infer that Compterosmittia croizati, known from Brazil and Venezuela (Mendes et al. 2004) and Parachironomus yanomami described from Brazil (Spies et al. 1994) would represent the Neotropical component. Within this component, genera such as Diplosmittia, Goeldichironomus, Labrundinia, Lipurometriocnemus, Pentaneura and Polypedilum (Asheum) possess a Pan-American distribution, having secondarily dispersed into the southern Nearctic via Central America or the Caribbean (Reiss and Sublette 1985). According to Jacobsen and Perry (2002) Manoa pahayokeensis Jacobsen \& Perry would belong to the fauna with primarily Neotropical or pantropical distribution. Other genera such as Microchironomus and Orthocladius are most widespread in the Holarctic region. Paralauterborniella, monotypic for $P$. nigrohalteralis (Malloch), has almost a worldwide distribution, only unrecorded for the Australian region (Sæther and Spies 2013). Spies and Reiss (1996) catalogued information and references for all chironomid taxa known from the entire Neotropical Region. However, no species was documented from the Dominican Republic or Haiti. Our study recorded 44 chironomid species in the Dominican Republic.

Assuming the limited duration and extension of our study, this species richness documented here is probably lower than the true richness of chironomid fauna in the Dominican Republic. Comparing our results with Ferrington et al. (1993), who sampled in a mountain stream during one year in the neighbouring island of Puerto Rico, we could expect that some species of the following genera are still found in streams of the Dominican Republic: Ablabesmyia, Corynoneura, Djalmabatista, Larsia, Paratendipes, Rheotanytarsus, Skutzia and Thienemanniella. Additional orthoclad genera were found on Saint Vincent by Saether (1981): Bryophaenocladius, Eurycnemus, Onconeura, Paraphaenocladius and Smittia. A study performed by Anderson et al. (2014) on San Salvador Island (Bahamas) identified only 12 chironomid species. The authors suggested that low diversity might occur on individual islands, with a much larger collective community in the Bahamas as a whole. According to Bass (2003), other important factors influencing the diversity of freshwater macroinvertebrate communities on Caribbean islands probably include climate and island dispersal capabilities or limitations of specific populations.

Although our results document a relatively small chironomid community in the Dominican Republic, we believe that collections in different periods 
(including both the rainy and dry seasons) and broadening the variety of sampling habitats and geographic area will reveal much greater diversity than currently detected. While recent years have seen increased activity concerning the chironomid fauna in the Neotropical region, the knowledge of the diversity and taxonomy as well as biogeography and phylogeny, especially in the Central America and Caribbean region, remains fragmentary. Thus, additional inventories are required to discover and analyse possible areas of endemism in the Greater Antilles archipelago. The present study contributes to the knowledge of chironomid fauna in the Dominican Republic and will hopefully motivate further studies in the area.

\section{Acknowledgements}

The authors extend their thanks to Martin Spies and Marion Kotrba, who provided us with working space in the Zoologische Staatssammlung München (ZSM). Thanks also to Ruth Bastardo from the Institute of Botanical and Zoological Investigations (Dominican Republic) for her help in planning fieldwork. We are greatly indebted to Juan Carlos Núñez for his assisting in the field and information from Dominican Republic. Many thanks to Anthony Kiszewski, his support and company made the collection of material an enjoyable experience. We are very grateful to Whit Farnum for the assistance in the preparation of the map. Collecting in Dominican Republic was possible thanks to the generosity of George Putnam, through a Putnam Expedition Grant from the Museum of Comparative Zoology at Harvard University. F. L. Silva was supported by a Postdoctoral Fellowship from the Coordination for the Improvement of Higher Education Personnel (CAPES).

\section{References}

Andersen, T., Mendes, H., F, and Pinho, L.C. 2015. Mariambera, a new genus of Orthocladiinae from Brazil (Insecta: Diptera, Chironomidae). - Studies on Neotropical Fauna and Environment 50(1): 24-30.

Andersen, T. and Pinho, L.C. 2014. A new species of Saetherocryptus Andersen et Mendes, 2007 (Diptera: Chironomidae, Orthocladiinae) from the Amazon rainforest, Brazil. - Norwegian Journal of Entomology 61: 160-164.

Anderson, A., Kranzfelder, P., Egan, A. and Ferrington, L.C. Jr. 2014. A Survey of Neotropical Chironomidae (Diptera) on San Salvador Island, Bahamas. - Florida Entomologist 97(1): 304-308.
Bass D. 2003. A comparison of freshwater macroinvertebrate communities on small Caribbean islands. - Bioscience 53(11): 1094-1100.

Cranston, P.S. and Epler, J.H. 2013. The larvae of Tanypodinae (Diptera: Chironomidae) of the Holarctic region - Keys and diagnoses. In Andersen, T., Cranston, P.S. and Epler, J.H. (Eds) Chironomidae of the Holarctic Region - Keys and diagnoses. Part 1. Larvae. - Insect Systematics \& Evolution, Supplement 66: 39-136.

Epler, J.H., Ekrem, T. and Cranston, P.S. 2013. The larvae of Chironominae (Diptera: Chironomidae) of the Holarctic region - Keys and diagnoses. In Andersen, T., Cranston, P.S. and Epler, J.H. (Eds) Chironomidae of the Holarctic Region - Keys and diagnoses. Part 1. Larvae. - Insect Systematics \& Evolution, Supplement 66: 387-556.

Ferrington, L.C. Jr. 2008. Global diversity of nonbiting midges (Chironomidae; Insecta-Diptera) in freshwater. - Hydrobiologia 595: 447-455.

Ferrington, L.C. Jr., Buzby, K.M. and Masteller, E.C. 1993. Composition and Temporal Abundance of Chironomidae Emergence from a Tropical Rainforest Stream at El Verde, Puerto Rico. - Journal of the Kansas Entomological Society 66(2): 167-180.

Grund, M. 2004. Chironomids (Diptera: Chironomidae) of Dominican amber. Ablabesmyia electrohispaniolana, sp.n. and paleoecological indications due to subfamily proportions. - Insect Systematics and Evolution 36: 29-34.

Grund, M. 2006. Chironomidae (Diptera) in Dominican amber as indicators for ecosystem stability in the Caribbean. - Palaeogeography, Palaeoclimatology, Palaeoecology 241: 410416.

Jacobsen, R.E. and Perry, S.A. 2002. A new species of Manoa (Diptera: Chironomidae) from Everglades National Park. - Journal of the North American Benthological Society 21(2): 314-325.

Lenat, D.R. and Resh, V.H. 2001. Taxonomy and stream ecology - The benefits of genus- and species-level identifications. - Journal of the North American Benthological Society 20(2): 287-298.

Margalef, R. 1986. Limnología del Lago Enriquillo. (República Dominicana). - Oecologia Aquatica 8: 1-10.

Mendes, H.F., Andersen, T. and Sæther, O.A. 2004. A review of Antillocladius Sæther, 1981; 
Compterosmittia Sæther, 1981 and Litocladius new genus (Chironomidae, Orthocladiinae). Zootaxa 594: 1-82.

Oliveira, C.S.N., Silva, F.L. and Trivinho-Strixino, S. 2013. Thalassomyia gutae sp. n., a new marine chironomid (Chironomidae: Telmatogetoninae) from the Brazilian coast. Zootaxa 3701: 589-595.

Perez-Gelabert, D.E. 2008. Arthropods of Hispaniola (Dominican Republic and Haiti): A checklist and bibliography. - Zootaxa 1831: 1-530.

Pinder, L.C.V. 1983. The larvae of Chironomidae (Diptera) of the Holarctic region - Introduction. - Entomologica Scandinavica Supplement, 19: 7-10.

Pinder, L.C.V. 1986. The pupae of Chironomidae (Diptera) of the Holarctic region - Introduction. - Entomologica Scandinavica Supplement, 28: 5-7.

Pinder, L.C.V. 1989. The adult of Chironomidae (Diptera) of the Holarctic region - Introduction. - Entomologica Scandinavica Supplement, 34: 5-9.

Reiss, F. and Sublette, J.E. 1985. Beardius, new genus with notes on additional Pan-American taxa. - Spixiana, Supplement 11: 179-193.

Roback, S.S. 1987. The immature chironomids of the eastern United States. IX. Pentaneurini -Genus Labrundinia with the description of some Neotropical material. - Proceedings of the Academy of Natural Sciences of Philadelphia 139: 159-209.

Sæther, O.A. 1981. Orthocladiinae (Diptera: Chironomidae) from the British West Indies, with descriptions of Antillocladius n. gen., Lipurometriocnemus n. gen., Compterosmittia n. gen. and Diplosmittia. - Entomologica Scandinavica Supplement, 16: 1-46.

Sæther, O.A., Andersen, T., Pinho, L.C. and Mendes, H.F. 2010. The problems with Polypedilum Kieffer (Diptera: Chironomidae), with the description of Probolum subgen. n. Zootaxa 2497: 1-36

Sæther OA, Ekrem T. 2003. Biogeography of Afrotropical Chironomidae (Diptera), with special reference to Gondwanaland. - Cimbebasia 19: 175-191.

Sæther, O.A. and Spies, M. 2013. Fauna Europaea: Chironomidae. In: Pape T, Beuk P. (Eds) Fauna Europaea: Diptera, version 2.6. http:// www.faunaeur.org/
Silva, F.L. and Ekrem, T. 2015. Phylogenetic relationships of non-biting midges in the subfamily Tanypodinae (Diptera: Chironomidae) inferred from morphology. - Systematic Entomology xx: xx-xx. (Early View)

Silva, F.L., Fonseca-Gessner, A.A. and Ekrem, T. 2014a. A taxonomic revision of genus Labrundinia Fittkau, 1962 (Diptera: Chironomidae: Tanypodinae). - Zootaxa 3769: 1-185.

Silva, F.L., Oliveira, C.S.N. and Trivinho-Strixino, S. 2014b. Metapelopia corbii gen. n., sp. n., a new Tanypodinae (Diptera: Chironomidae) from the Neotropical Region. - Annales de Limnologie - International Journal of Limnology 50: 85-95.

Silva, F.L. and Wiedenbrug, S. 2015. Amazonimyia gigantae gen. n., sp. n., a new Tanypodinae (Diptera: Chironomidae) from the Neotropical Region. - Zootaxa,3947(2): 275-281.

Siri, A. and Donato, M. 2014. Monopelopia caraguata (Chironomidae: Tanypodinae: Pentaneurini) and Phytotelmatocladius delarosai (Chironomidae: Orthocladiinae): two phytotelmatous chironomids distributed from Florida to Argentina. - Florida Entomologist 97(3): 1226-1231.

Siri, A. and Donato, M. 2015. Phylogenetic analysis of the tribe Macropelopiini (Chironomidae: Tanypodinae): adjusting homoplasies. - Zoological Journal of the Linnean Society 174: 74-92.

Spies, M., Andersen, T., Epler, J.H. and Watson, C.N. Jr. 2009. Chironomidae (non-biting midges). Manual of Central American Diptera. (eds Brown BV, Borkent A, Cumming JM, Wood DM, Woodley NE, Zumbado M), pp. 437-480. NRC Research Press, Ottawa.

Spies, M., Fittkau, E.J. and Reiss, F. 1994. The adult males of Parachironomus Lenz, 1921, from the Neotropical faunal region (Insecta, Diptera, Chironomidae). - Spixiana Supplement 20: 61-98.

Spies, M. and Reiss, F. 1996. Catalog and bibliography of Neotropical and Mexican Chironomidae (Insecta, Diptera). - Spixiana, Supplement 22: 61-119.

Trivinho-Strixino, S., Silva, F.L. and Oliveira, C.S.N. 2013. Tapajos cristinae n. gen., n. sp. (Diptera: Chironomidae: Chironominae) from Neotropical Region. - Zootaxa 3710: 395-399. 
Trivinho-Strixino, S., Wiedenbrug, S. and Silva, F.L. 2015. New species of Tanytarsus van der Wulp (Diptera: Chironomidae: Tanytarsini) from Brazil. - European Journal of Environmental Sciences 5(1): 92-100.
Watson, C.N. Jr. and Heyn, M.W. 1992. A preliminary survey of the Chironomidae (Diptera) Of Costa Rica, with emphasis on the lotic fauna. Netherlands Journal of Aquatic Ecology 26(24): 257-262.

Article submitted 18. September 2015, accepted 3. November 2015, published 22. December 2015. 